\title{
New Materials in Dentistry
}

\author{
J. Kiann (Jalil Kiann), M. Luliak (Milan Luliak)
}

SEUC PhD Program in Health Management and Public Health, Dentist, Monchengladbach, DE.

\section{E-mail address:}

j.kiann@web.de

\section{Reprint address:}

Jalil Kiann

SEUC PhD Program in Health Management and Public Health

Dentist, Lindenstraße 171

41063 Monchengladbach

Germany

Source: Clinical Social Work and Health Intervention

Volume: 12

Issue: 3

Pages: $19-23$

Cited references: 20

\section{Reviewers:}

Eliska Knoskova

Bratislava, SK

Claus Muss

I-GAP Zurich, CH

\section{Keywords:}

Titanium. Zirconia. Dental Implants. Biomaterial. Ceramic.

\section{Publisher:}

International Society of Applied Preventive Medicine i-gap

CSWHI 2021; 12(3): 19 - 23; DOI: 10.22359/cswhi_12_3_03 CC Clinical Social Work and Health Intervention

\section{Abstract:}

The use of an appropriate implant biomaterial significantly determines the success of implants. The biologic environment where implants are placed does not necessarily accept any material. Therefore, biologic performance can be optimized by selecting implants that reduce negative biologic response while at the same time functioning adequately. Besides, clinicians should be knowledgeable of different biomaterials used for purposes of dental implants. The purpose of this paper is to provide an overview on the issue of dental implants. Some of the implants discussed in the paper include titanium and zirconia implants. Furthermore, the paper discusses how physical properties of the materials influence the treatment outcome. 


\section{Introduction}

Oral implants have become a reliable form of treatment to replace missing teeth since they were first introduced. The properties of materials used during implants, which can be either chemical or physical, determine the clinical outcome of the process. The properties are the implant microstructure, surface characteristics and composition, and other factors related to design. In addition, the implant material ought to be biocompatible, and have strength, corrosion, toughness, as well as be resistant to fracture and wear. Dental implants can be made from materials such as polymers, ceramics, and metals. The use of new materials in dentistry has helped to improve the quality of implants and dental health. Modern dentistry has begun to recognize, understand, and apply biotechnology.

\section{Methods}

The use of new materials in dentistry has led to significant improvements in the quality of implants and dental health. In European countries such as Germany, scientists have developed new materials for use during dental implants. ${ }^{1}$ One of the most promising materials used in dentistry is Polyetheretherketone (PEEK). The material is preferred by dentists since it has excellent mechanical characteristics. When this material is used, bone-related cells might not recognize an implant as a foreign object, and this makes healing to happen faster and firmly. ${ }^{2}$ Technological advancements such as the use of milling technology and three dimensional printing have contributed to cost-efficient imaging, thus maximizing the comfort of implants among patients. Besides, custom dental implants designed by Replicate Dental Implant System in Berlin, Germany, are more effective while doing implants than the traditional endosteal implants.

Other materials used during modern implants include titanium and Zirconium. ${ }^{3}$ Titanium is preferred as a material of choice because of the typical properties it possesses such as resistance to doses of chemicals and high passivity. Additionally, it is possible for the material to repair on itself if damaged. ${ }^{4}$ Titanium is also preferred because it has few drawbacks, but the use of this material has disadvantages because of the unaesthetic nature in the frontal area. However, the limitations of titanium are being overcome with the development of ceramic implants. ${ }^{5}$ Zirconia has also become a material of choice during dental implants, and its preference emanates from the mechanical properties, which make the material suitable in fabricating dental implants. ${ }^{6}$ The material has excellent mechanical properties such as superior wear resistance and corrosion, and high flexural strength. Moreover, zirconia has low values in terms of fracture strength for both the unloaded and loaded implants.

\section{Results}

Implant therapy has undergone tremendous progress due to the rise of modern innovations. ${ }^{7}$ Bone-augmentation techniques have improved implant therapy. Some techniques such as sinus floor elevation and guided bone regeneration have been instrumental in correcting bone defects at implant sites. Furthermore, improvements in pre-surgical planning and preoperative analysis have been wit-

\footnotetext{
${ }^{1}$ Knaus, J., Schaffarczyk, D., \& Colfen, H. (2019). On the future design of bio-inspired polyetheretherketone dental implants. Macromolecular Bioscience, 20(1), 1900239

${ }^{2}$ Archer, B. P., \& Reddy, L. (2016). Preliminary investigative study for custom designed immediate dental implants. Oral Scientific, 123(2), E26.

${ }^{3}$ Duraisamy, V., Sarate, S. (2017). Dental implant materials, implant design, and role of FEA-A brief review. Journal of Evolution of Medicine and Dental Sciences, 644), 3487-3492.

${ }^{4}$ Shen, Z., Liu, Y., \& Feng, H. (2018). Customized all-ceramic dental prostheses: A graphic introduction to advanced materials and procedures. Amsterdam: Butterworth-Heinemann.

${ }^{5}$ Osman, R. B., \& Swain, M. V. (2015). A Critical Review of Dental Implant Materials with an Emphasis on Titanium versus Zirconia. Materials (Basel, Switzerland), 8(3), 932-958.

${ }^{6}$ Health Innovation (2020). Ceramic dental implants: Innovation in dentistry. Retrieved from: https://www.innovationnewsnetwork.com/ceramic-dental-implants-innovation-in-dentistry/5955/

${ }^{7}$ Buser, D., Sennerby, L., \& De Bruyn, H. (2016). Modern implant dentistry based on osseointegration: 50 years of progress, current trends and open questions. Periodontology 2000, 73(1), 7-21.
} 
nessed with the introduction of imaging techniques. ${ }^{8}$ Germany is the leading nation in the manufacture of high quality dental implants. The dental implants associated with NDI Medical adhere to protocol and comply with high standards of quality. In addition to this, the dental implants manufactured in Germany facilitate the surgical process and result to positive outcomes for patients. The quality titanium used to manufacture German implants guarantees comfort, functionality, and restores aesthetics.

The shortcomings associated with dental implants have led to the use of new implant materials such as Hafnium, Niobium, and Tantalum. ${ }^{9}$ These materials are preferable because they fulfill functional requirements and have pleasing esthetic features..$^{10}$ The use of Hafnium as a biochemical material in manufacturing implants is beneficial since it has improved mechanical properties such as high creep strength. Furthermore, tantalum (Ta) and niobium (Na) demonstrate improved mechanical properties when used in combination with Ti alloys. ${ }^{11}$ The incorporation of alloys with titanium yields success when having dental implants. This is because the combination improves the mechanical properties such as pore size, corrosion resistance, and materials distribution.

Adverse reactions are likely to be witnessed when biomaterials are used to perform dental implants. The use of several strategies could help to improve the biocompatibility of dental materials manufactured and used in Germany. ${ }^{12}$ One of the strategies that can help to improve the technical conditions includes developing in vitro tests. This way, it is possible to generate appropriate data on how the materials can be used while performing implants. Besides, research should be conducted on interactions between the material and tissues. ${ }^{13}$ With this strategy, it is possible to come up with new and biocompatible materials. Also, the research on different types of patients and their susceptibility to exposure is crucial in defining high risk groups. Another strategy that can improve the biocompatibility of new dental materials is improved education among dentists on how to use the materials.

\section{Discussion}

The use of new materials in implant-supported prosthetic restorations is important in prosthetic dentistry. ${ }^{14}$ Dental implants have high success rates and they provide many years of clinical service. However, biological and technical complications are common in restorations supported by implants. Some materials might contribute to technical complications such as abutment, implant fractures, and loosening of the fractures. ${ }^{15}$ Prosthetic treatments are available to mitigate the negative clinical effects of implants. A common treatment option is the use of abutment material such as hybrid, zirconia, and titanium. Therefore, prosthetic treatment guidelines could be considered when planning for implants to yield positive outcomes after a dental implant.

Lithium disilicate ceramics are other types of new materials used for dental implants. ${ }^{16}$ Lithium

${ }^{8}$ NDI Medical (2020). German dental implant brands and manufacturers. Retrieved from: https://ndimedical.eu/our-articles/german-dental-implants/

${ }^{9}$ Rajaraman, V., Dhanraj, M., \& Jain, A. R. (2018). Dental implant biomaterials-Newer metals and their alloys. Drug Invention Today, 10(6), 986-989

${ }^{10}$ Amin, A. M. A. J. (2016). Dental implantology and biomaterial. Rijeka, Croatia: InTech.

${ }^{11}$ Khurshid, Z., Najeeb, S., Zafar, M. S., \& Sefat, F. (2019). Advanced dental biomaterials. Duxford, United Kingdom: Elsevier/Woodhead Publishing.

${ }^{12}$ Schmalz, G. (2014). Strategies to improve biocompatibility of dental materials . Current Oral Health Reports, 1, 222-231.

${ }^{13}$ Shen, J. Z., \& Kosmač, T. (2014). Advanced ceramics for dentistry. Waltham, MA: Butterworth-Heinemann.

${ }^{14}$ Glucker, C., Hahnel, S., \& Rauch, A. (2020). Attitude and treatment options in implant-supported prosthetics: A survey among a cohort of German dentists. The Journal of Advanced Prosthodontics, 12(1), 15.

${ }^{15}$ Shrestha, B., Basnet, B.B. \& Adhikari, G. (2020). A questionnaire study on the impact on oral health-related quality of life by conventional rehabilitation of edentulous patient. BDJ Open, 6(3), 1-5.

${ }^{16}$ Zarone, F., Ferrari, M., et al (2016). Digitally oriented materials: Focus on lithium disilicate ceramics. International Journal of Dentistry, Article ID 9840594, 1-7. 
disilicate glass is one of the most common restorative materials during dental implants. The material is preferred for its outstanding optical properties such as ease of processing, minimal invasiveness, and its potential for adhesive bonding. Furthermore, the material has a survival rate of $71.4 \%$ percent when used within a span of 10 years, but could result to complications such as recessions, postoperative sensitivity, and marginal discolorations. Nevertheless, the anatomically shaped, monolithic lithium disilicate has been introduced, and it promises favorable outcomes when used for dental implants.

Apart from titanium, zirconia, lithium disilicate and other materials, dental implants are also done using carbon nanotubes..$^{17}$ Advancements in dental implant technology have led to reductions in cost and contributed to success of orthodontic procedures. CNT-based nanocomposites are materials used in the development of new materials with mechanical properties compatible with the bone. Currently, dentists use CNT nanocomposites because of their biocompatibility. ${ }^{18}$ The composites used are those formed using glassy carbon, zirconia, titanium, and hydroxyapatite. Thus, nanocomposite materials that incorporate CNTs produce affordable and durable dental implant materials.

The biomaterial used for purposes of an implant should have several properties ${ }^{19}$ Some of the properties include elasticity, ductility, toughness and hardness, strength, tensile, shear, and compressive strength. The modulus of elasticity in the implant material should be comparable to the bone. This ensures uniform stress distribution during implant and minimizes movement at the bone interface. The minimum ductility required for the implant material is $8 \%$, and this helps to contour and shape an implant. ${ }^{20}$ Yield and fatigue strength is essential in preventing brittle fracture, especially when the implant experiences cyclic loading. In addition to this, hardness decreases wear of the implant material while the implant is prevented from fracture due to toughness. Also, an implant ought to have high compressive and tensile strength to improve functional stability and prevent the occurrence of fractures.

\section{Conclusion}

Dental implants refer to artificial prosthesis inserted into a patient's gum line to replace infected or damaged teeth. Successful replacement of a tooth is essential in improving and restoring a patient's quality of life through improved eating experience and bite, and can serve an individual for a long time. Some of the new materials used for dental implants in the German context include titanium, zirconia, and lithium, which are made of ceramic. Moreover, carbon nanotubes have emerged as advanced materials for use in dental implants. The new materials are preferred because of their outstanding properties, which make them to last long and serve patients as intended.

\section{References}

1. AMIN A M A J (2016) Dental implantology and biomaterial. Rijeka, Croatia: InTech.

2. ARCHER B P, \&AMP; REDDY L (2016) Preliminary investigative study for custom designed immediate dental implants. Oral Scientific, 123(2), E26.

3. BUSER D, SENNERBY L, \&AMP; DE BRUYN H (2016) Modern implant dentistry based on osseointegration: 50 years of progress, current trends and open questions. Periodontology 2000, 73(1), 7-21.

4. DURAISAMY V, SARATE S (2017) Dental implant materials, implant design, and role of FEA-A brief review. J of Evolution of Medicine and Dental Sciences, 644), 3487-3492.

5. DURACCIO D, MUSSANO F, \&AMP; FAGA M G (2015) Biomaterials for dental

\footnotetext{
${ }^{17}$ Teh, S. J., \& Lai, C. W. (2019). Applications of nanocomposite materials in dentistry. Elsevier: Woodhead Publishing.

${ }^{18}$ Duraccio, D., Mussano, F., \& Faga, M. G. (2015). Biomaterials for dental implants: Current and future trends. Journal of Material Science, 50, 4779-4812.

${ }^{19}$ Saini, M., Singh, Y., Arora, P., Arora, V., \& Jain, K. (2015). Implant biomaterials: A comprehensive review. World Journal of Clinical Cases, 3(1), 52-57.

${ }^{20}$ Kelly, J. R. (2016). Ceramics in dentistry: Principles and practice. Chicago: Quintessence Publishing co.
} 
implants: Current and future trends. J of Material Science, 50, 4779-4812.

6. GLUCKER C, HAHNEL S, \&AMP; RAUCH A (2020) Attitude and treatment options in implant-supported prosthetics: A survey among a cohort of German dentists. The Journal of Advanced Prosthodontics, 12(1), 15.

7. HEALTH INNOVATION (2020) Ceramic dental implants: Innovation in dentistry. Retrieved from: https://www.innovationnewsnetwork.com/ceramic-dental-implants-innovation-in-dentistry/5955/.

8. KELLY J R (2016) Ceramics in dentistry: Principles and practice. Chicago: Quintessence Publishing Co.

9. KHURSHID Z, NAJEEB S, ZAFAR M S, \&AMP; SEFAT F (2019) Advanced dental biomaterials. Duxford, United Kingdom: Elsevier/Woodhead Publishing.

10. KNAUS J, SCHAFFARCZYK D, \&AMP; COLFEN H (2019) On the future design of bio-inspired polyetheretherketone dental implants. Macromolecular Bioscience, 20(1), 1900239.

11. NDI MEDICAL (2020) German dental implant brands and manufacturers. Retrieved from: https://ndimedical.eu/our-articles/german-dental-implants/.

12. OSMAN R B, \&AMP; SWAIN M V (2015) A Critical Review of Dental Implant Materials with an Emphasis on Titanium versus Zirconia. Materials (Basel, Switzerland), 8(3),932-958.

13. RAJARAMAN V, DHANRAJ M, \&AMP; JAIN A R (2018) Dental implant biomaterials-Newer metals and their alloys. Drug Invention Today, 10(6), 986-989.

14. SAINI M, SINGH Y, ARORA P, ARORA V, \&AMP; JAIN K (2015) Implant biomaterials: A comprehensive review. World Journal of Clinical Cases, 3(1), 52-57.

15. SHEN Z, LIU Y, \&AMP; FENG H (2018) Customized all-ceramic dental prostheses: A graphic introduction to advanced materials and procedures. Amsterdam: Butterworth-Heinemann.

16. SHRESTHA B, BASNET B B, \&AMP; ADHIKARI G (2020) A questionnaire study on the impact on oral health-related quality of life by conventional rehabilitation of edentu- lous patient. BDJ Open, 6(3), 1-5.

17. SCHMALZ G (2014) Strategies to Improve Biocompatibility of Dental Materials. Current Oral Health Reports, 1, 222-231.

18. SHEN J Z, \&AMP; KOSMAC T (2014) Advanced Ceramics for Dentistry. Waltham, MA: Butterworth-Heinemann.

19. TEH S J, \&AMP; LAI C W (2019) Applications of nanocomposite materials in dentistry. Elsevier: Woodhead Publishing.

20. ZARONE F, FERRARI M, ET al (2016) Digitally oriented materials: Focus on lithium disilicate ceramics. International Journal of Dentistry, Article ID 9840594, 1-7. 